ЕКОЛОГІЯ

ECOLOGY

https://doi.org/10.15407/dopovidi2021.06.139

УДК $539.1,550.422,550.35$

Н.I. Сватюк ${ }^{\mathbf{1}}$, https://orcid.org/0000-0001-9022-9252

B.I. Роман ${ }^{1}$, https://orcid.org/0000-0003-2499-8357

О.М. Поп ${ }^{1}$, https://orcid.org/0000-0002-5690-1030

O.I. Симканич ${ }^{2}$, https://orcid.org/0000-0002-9948-1742

І.В. Пилипчинець ${ }^{\mathbf{1}}$, https://orcid.org/0000-0002-0120-7703

${ }^{1}$ Інститут електронної фізики НАН України, Ужгород

2 ДВНЗ “Ужгородський національний університет"

E-mail: natashasim777@gmail.com, viktoriyaroman11@gmail.com

\title{
Радіоізотопні дослідження басейну річки Тиса, Ужанський масив
}

Представлено членом-кореспондентом НАН Украйни Г.М. Гомонай

Наведено результати застосування ядерно-фізичних методів дослідження радіоізотопного складу донних відкладів та грунтів басейну р. Тиса на прикладі р. Уж, територія Закарпаття. Для отримання бази даних щодо вмісту природних та штучних гамма-активних нуклідів використано метод низькофонової гаммаспектрометрії. Показано можливість якісної оцінки хімічних компонент $U / T h / K$ у донних відкладах $p$. Уж. Одержані результати радіоізотопних досліджень дозволять моделювати процеси міграції гамма-активних нуклідів із водосховищ, у грунтові горизонти досліджуваних територій, а також прогнозувати транскордонні міграції гамма-активних нуклідів.

Ключові слова: радіоізотопний склад, техногенні й природні нукліди, питомий вміст, акумуляція-поширення, уран/торієві компоненти.

Гірські системи мають особливий ізотопний та мікроелементний склад грунтів і водних ресурсів та істотно впливають на екологічні показники значних прилеглих територій. У цьому контексті важливу роль відіграє радіоекологічний моніторинг, особливо у межах природно-заповідного фонду, адже він дозволяє врахувати особливості кліматичних, морфологічних і геологічних умов територій при встановленні нормативів стану об'єктів довкілля. Вкрай актуальні такі дослідження для молодих гір, якими є Карпати, зокрема території Закарпатської обл., яка заслуговує особливої уваги, адже зональність території області з виділенням гірських, передгірських і низовинних районів потребує визначення фонових

Ц и т у в ан н я: Сватюк H.I., Роман В.І., Поп О.М., Симканич О.І., Пилипчинець I.В. Радіоізотопні дослідження басейну річки Тиса, Ужанський масив. Допов. Наи. акад. наук Укр. 2021. № 6. С. 139-145. https://doi.org/10.15407/dopovidi2021.06.139 


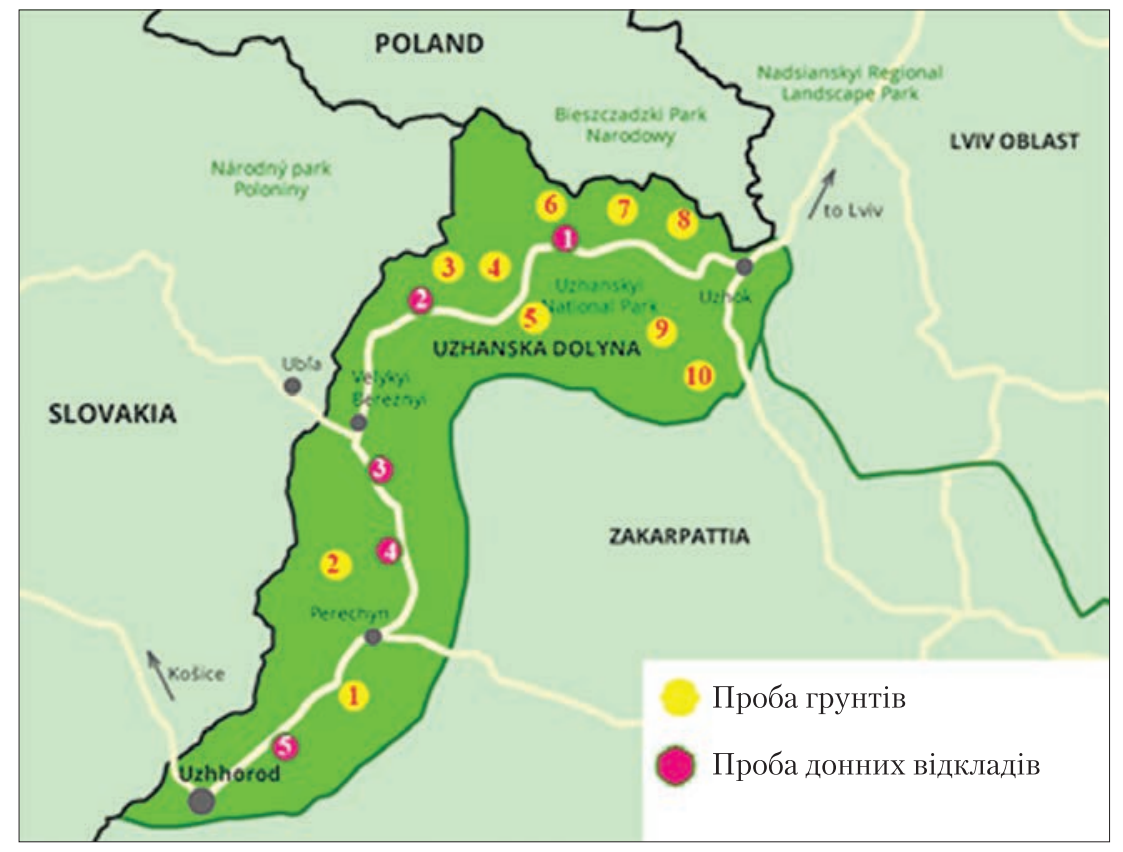

Puc. 1. Ділянки відбору проб грунтів та донних відкладів р. Уж в Ужанському регіоні

значень вмісту питомої активності гамма-активних нуклідів (ГАН) у об'єктах навколишнього природного середовища. Крім того, географічне розташування Закарпатської обл. викликає інтерес у проведенні подібних досліджень, тому що екологічний стан цієї території значною мірою визначає екологічний стан територій країн Євросоюзу. Цікавим є і зворотній зв’язок щодо можливості транскордонного переносу забруднювальних речовин на територію Закарпаття, оскільки Карпатські гори - це своєрідний бар'єр міграції техногенних факторів. Водночас у науковій літературі практично відсутні дані про проведення таких досліджень. Тому, на наш погляд, перспективним є радіоізотопне дослідження Ужанського національного парку, що входить до складу транскордонного українсько-польсько-словацького біосферного резервату “Східні Карпати”, об’єкту всесвітньої спадщини ЮНЕСКО і є територією Смарагдової мережі [1]. Важливо також вивчати одну з головних водних артерій регіону (ліву притоку р. Тиса) р. Уж, яка, протікаючи поблизу державного кордону, нижче м. Ужгород, перетинає державний кордон зі Словаччиною.

У роботі розглядаються регламенти та процедура встановлення радіаційних показників досліджуваних територій: схема пробовідборів, вибір ізотопів-міток для їх характеристики та особливості низькофонових гамма-спектрометричних досліджень для встановлення стандартів вмісту / співвідношення кларків хімічних елементів U/Th, показана можливість прогнозування транскордонної міграції ГАН прилеглих територій.

Методологія. Вибір положення та числа точок пробовідбору мають визначатися як геоморфологічними показниками досліджуваної території, так й інтенсивністю техногенних факторів. Зауважимо, що здатність грунтів акумулювати радіонукліди залежить від співвідношення в них органічних компонент, як гумусу, так і мінеральної складової. Так, здат- 
ність гумусу адсорбувати катіони радіоактивних атомів у 10 раз вища, у порівнянні з мінеральними колоїдами [2]. Середня концентрація радію-226 в грунтах становить 26 Бк/кг (0,7 нКі/кг), свинцю-210 і полонію-210 - приблизно, 33 Бк/кг (0,9 нКі/кг), причому, близько 30\% цих ізотопів потрапляє в грунт з атмосферними опадами. Активність гірських порід і грунтів (за рахунок рубідію-87) коливається від 1 до 200 Бк/кг (0,036-5,5 нКі/кг), інші природні радіонукліди містяться в значно менших кількостях. Загальна питома $\gamma$-активність грунту становить, приблизно, 550-740 Бк/кг (15-20 нКі/кг). Відбір проб грунтів і донних відкладів р. Уж (Ужанського регіону) здійснювали з урахуванням висоти місцевості, типу грунтів, морфологічних особливостей річки та інших критеріїв. На рис. 1 представлено ділянки відбору проб грунтів і донних відкладів Ужанського регіону з відображенням геоморфологічних відмінностей території.

Зразки для вимірювань відбиралися за правилом конверту в контрольних точках ділянки розміром $100 \times 100 \mathrm{~cm}^{2}$. Фіксувались координати точок пробовідбору за допомогою GPS-навігації. Проби донних відкладів відбирались щоквартально, а грунти - одноразово з урахуванням стаціонарності системи [3, 4].

Оскільки кожний зразок намулу / грунту давав інформацію про питомий вміст не одного, а набору ГАН техногенного та природного походження - для систематизації та узагальнення даних радіоекологічного моніторингу використовували метод багатовимірного статистичного аналізу. Завдання, які вирішували - встановлення однорідності сукупності ознак пробовідборів, ступеню статистичної близькості точок пробовідбору, тісноти статистичного зв’язку та кореляції ГАН природних рядів, а також впливу різного роду латентних показників. Перспективним є метод встановлення кларкових уран/торієвих/калієвих співвідношень через значення питомих активностей $\frac{A^{(T h)}}{A^{(U)}}, \frac{A^{(T h)}}{A^{(40 K)}}$ який виражається через формули [5]:

$$
\frac{N_{T h}}{N_{U}} \cong \frac{T_{1 / 2}^{(T h)}}{T_{1 / 2}^{(U)}} \cdot \frac{A^{(T h)}}{A^{(U)}}, \quad \frac{N_{T h}}{N_{40 K}} \cong \frac{T_{1 / 2}^{(T h)}}{T_{1 / 2}^{(40 K)}} \cdot \frac{A^{(T h)}}{A^{(40 K)}}
$$

де $\frac{T_{1 / 2}^{(T h)}}{T_{1 / 2}^{(U)}}\left(\frac{T_{1 / 2}^{(T h)}}{T_{1 / 2}^{(40 K)}}\right)-$ відношення періодів напіврозпадів ізотопів ${ }^{232} \mathrm{Th}$ та ${ }^{238} \mathrm{U},\left({ }^{232} \mathrm{Th},{ }^{40} \mathrm{~K}\right)$. Знаючи питомий вміст ізотопів ${ }^{232} \mathrm{Th},{ }^{238} \mathrm{U},{ }^{40} \mathrm{~K}$ у складі хімічних елементів торію, урану та калію можна оцінити відношення кількостей хімічних елементів за числом атомів:

$$
\mathrm{U}: \mathrm{Th}: \mathrm{K} \text {. }
$$

Просторові закономірності розподілу радіоізотопного складу намулів та грунтів Ужанського масиву. Вибір об’єкту дослідження зумовлений віддаленістю його від джерел антропогенного впливу, вмістом низько- та високогірних ділянок території, а також таких, що знаходяться безпосередньо біля кордону. Результати фонового моніторингу є основою для встановлення стандартів питомого вмісту радіонуклідів і мікроелементного складу грунтів 


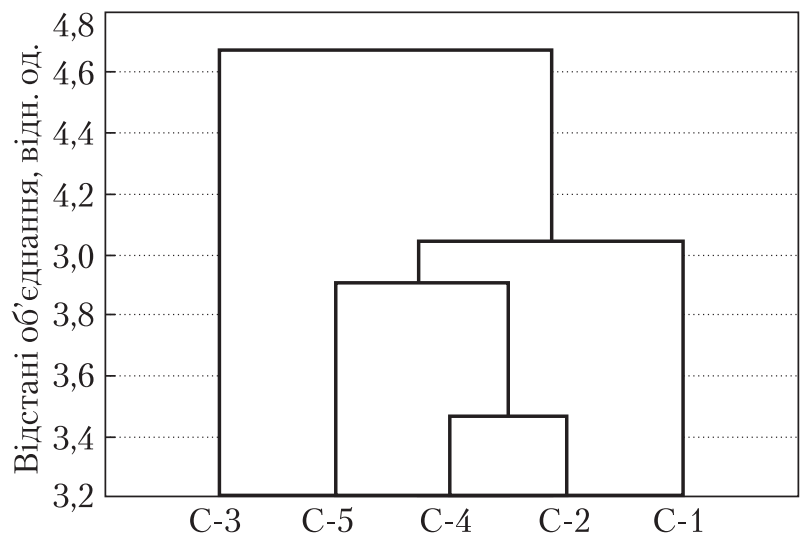

$\boldsymbol{P u c . 2 . ~ Р е з у л ь т а т и ~ к л а с т е р н о г о ~ а н а л і з у ~ с т а т и с т и ч н о і ̈ ~ б л и з ь к о с т і ~ т о ч о к ~ п р о б о в і д б о р у ~ д л я ~ в с ь о г о ~ м а с и в у ~ Г А Н ~}$ техногенного $\left({ }^{137} \mathrm{Cs}-i\right)$ та природного $\left({ }^{214} \mathrm{Bi}-i,{ }^{212} \mathrm{~Pb}-i,{ }^{40} \mathrm{~K}-i\right)$ походження $i=1-5$ вздовж русла р. Уж

та донних відкладів [6]. Вони дозволяють врахувати особливості геології й геохімії досліджуваних територій, впливу кліматичних та інших умов на формування природного фону.

Річка Уж - це одна з найбільших приток головної водної артерії регіону (р. Тиса). У табл. 1 містяться систематизовані дані за точками пробовідбору впродовж усього часу спостереження. Результати усередненого вмісту стандарту ГАН свідчать про збільшення питомого вмісту природнього ${ }^{40} \mathrm{~K}$ та техногенного ${ }^{137} \mathrm{Cs}$ у зразках намулів, при переході від висотних до низинних ділянок русла ріки [7]. Збільшення ${ }^{137} \mathrm{Cs}$ складової зумовлено саме антропогенним чинником, який зумовлений діяльністю людини на досліджуваній території.

На рис. 2 показано результати дослідження статистичної близькості точок пробовідбору вздовж русла р. Уж.

Розгляд діаграми вказує на те, що відбувається кластеризація між низинними точками пробовідбору 4 (с. Зарічево) та 5 (с. Оноківці). Проте, така ж залежність існує між точками 2 (с. Забрідь) та 4 (с. Зарічево), що може бути обумовлено подібним характером ант-

Таблиия 1. Усереднений питомий вміст (стандарт) ГАН у зразках намулів р. Уж за весь період спостереження: для вибраних точок пробовідбору, а також узагальнене значення (стандарт) для всього русла річки

\begin{tabular}{|l|c|c|c|c|}
\hline \multirow{2}{*}{$\begin{array}{c}\text { Номер пробовідбору, } \\
\text { населений пункт }\end{array}$} & \multicolumn{4}{|c|}{ Питома активність } \\
\cline { 2 - 5 } & ${ }^{40} \mathrm{~K}$, Бк/кг & ${ }^{137} \mathrm{Cs}$, Бк/кг & ${ }^{214} \mathrm{Bi}$, Бк/кг & ${ }^{212} \mathrm{~Pb}$, Бк/кг \\
\hline 1, с. Сіль & 333,6 & 3,6 & 21,6 & 23,6 \\
2, с. Забрідь & 320,7 & 3 & 16,6 & 17,4 \\
3, с. М. Березний & 295 & 3 & 20,9 & 18,8 \\
4, с. Зарічево & 335,5 & 4,1 & 21,6 & 24 \\
5, с. Оноківці & 377,9 & 4,1 & 24 & 2,5 \\
Дисперсія & 19,752 & 0,448 & 1,752 & 21,3 \\
Стандарт & 332,5 & 3,56 & 20,9 & \\
\hline
\end{tabular}


ропогенної активності цих ділянок русла р. Уж та схожими геохімічними факторами прилеглої території.

Фактор діяльності людини може знижувати ступінь статистичних залежностей між вмістом ГАН природних рядів у зразках намулів [8]. Це зменшує достовірність встановлення кларкових компонент для даного басейну, проте, їх оцінка із використанням формул (1) та (2) дає наступну характеристику кларків відношень кількостей хімічних елементів за числом атомів:

$$
\mathrm{U}: \mathrm{Th}: \mathrm{K}=1: 3: 11084 \text { ат.\%. }
$$

Таблиия 2. Усереднені показники

ГАН (стандарти) в грунтах гумусного/поверхневого горизонту території НПП “Ужанський”

\begin{tabular}{|l|c|c|c|}
\hline \multicolumn{2}{|c|}{ ГАН } & $\begin{array}{c}\text { Питома активність, } \\
\text { Бк/кг }\end{array}$ & Дисперсія \\
\hline${ }^{40} \mathrm{~K}$ & 554,6 & 131 \\
${ }^{\mathrm{P} я д ~}{ }^{238} \mathrm{U}$ & ${ }^{214} \mathrm{~Pb}$ & 31,6 & 3,16 \\
& ${ }^{214} \mathrm{Bi}$ & 32,5 & 2,91 \\
${ }^{\mathrm{P}}{ }^{2}{ }^{232} \mathrm{Th}$ & ${ }^{212} \mathrm{~Pb}$ & 38,06 & 6,32 \\
& ${ }^{212} \mathrm{Bi}$ & 35,6 & 6,72 \\
${ }^{137} \mathrm{Cs}$ & ${ }^{228} \mathrm{Ac}$ & 38,2 & 7,14 \\
& & 16,2 & 5,49 \\
\hline
\end{tabular}

Результати радіоізотопного дослідження грунтів Ужанського регіону показують збільшення питомого вмісту природного ${ }^{40} \mathrm{~K}$ для верхнього шару грунту, який складає 554,6 Бк/ кг. Для маркеру техногенного ${ }^{137} \mathrm{Cs} 16,2$ Бк/кг. Слід зазначити, що дані радіоекологічного дослідження для Ужанського регіону проведено тільки для поверхневих шарів грунту.

Із показників видно, що спостерігається зменшення кларкового компоненту торію та калію для досліджуваних територій у порівнянні із такими ж значеннями для намулів р. Уж, яка протікає досліджуваними територіями.

Кларковий вміст відношення U/Th для ППН “Ужанський” становить U:Th:K = $=1: 2,7: 10675$ ат. $\%$.

Висновки. У результаті проведеного радіоізотопного дослідження Ужанського регіону отримано усереднені показники (стандарти) питомого вмісту ГАН природного та техногенного походження. Показано особливості їх значень для ізольованих гірських районів Карпат, характер їх зміни для гірських та низинних ділянок басейну р. Уж. Отримані дані радіоізотопного дослідження дозволяють моделювати процеси міграції ГАН із донних відкладів у глиб грунтового ландшафту територій, що дозволяє прогнозувати транскордонну міграцію ГАН прилеглих територій.

Дослідження виконані в Інституті електронної фізики НАН України у рамках Гранту НАН України дослідницьким лабораторіям/групам молодих вчених НАН України для проведення досліджень за пріоритетними напрямами розвиту науки і техніки 2021-2022 рр. "Радіоекологічний моніторинг вмісту радіонуклідів у водно-грунтовому комплексі украӥнсъких Карпат: модель прогнозування й запобігання можливим катастрофічним наслідкам”.

\section{ЦИТОВАНА ЛІТЕРАТУРА}

1. Chau N.D., Lucyna R., Nowak J., Jodłowski P. Radium isotopes in the Polish Outer Carpathian mineral waters of various chemical composition. J. Environmental Radioactivity. 2012. 112. P. 38-44.

https://doi.org/10.1016/j.jenvrad.2012.03.010 
2. Badawy W.M., Duliu O.G., Frontasyeva M.V., Samman H.El. \& Faanhof A. Environmental radioactivity of soils and sediments: Egyptian sector of the Nile valley. Isotopes in Environmental and Health Studies. 2018. 54, Iss. 5. P. 535-547. https://doi.org/10.1080/10256016.2018.1482292

3. Охрана природы. Гидросфера. Общие требования к отбору проб донных отложений водных объектов для анализа на загрязненность: ГОСТ 17.1.5.01-80 [Введ. 01.01.81]. Москва: Госкомитет СССР по стандартам, 1981. 6 с.

4. Организация и проведение наблюдений за содержанием загрязняющих веществ в донных отложениях водных объектов: РД 52.24.609-2013. [Введ. 02.09.2013]. Ростов-на-Дону : Росгидромет, 2013. 43 с.

5. Dikiy N.P., Lyashko Yu.V., Medvedeva E. P., Medvedev, D. V, Parhomenko, Yu. G., Fedorets, I. D. The content of natural radioactive isotopes in soil of Kharkov region. Problems of atomic science and technology. Series: Nuclear Physics Investigations. 2017. 3 (109). P. 55-59.

6. Maslyuk V., Svatyuk N., Stets M., Frontasyeva M., Parlag O. Statistical regularities in the distribution of radionuclides in sediments of Transcarpathia mountain rivers. J. Environmental Radioactivity. 2013. 117. P. 9-12. https://doi.org/10.1016/j.jenvrad.2012.04.016

7. Svatiuk N.I., Symochko D.M.. Radioecology of Transcarpathian mountain Rivers: Time and Spatial Correlations. Nuclear Physics and Accelerators in Biology and Medicine. Fifth International Summer School edited by A.Dubnichkova, S. Dubnichka, C. Granja, C. Leroy, I. Stekl. AIP Conference Proceedings. 2010. 1204. P. 263-264.

8. Symkanich O., Maslyuk V., Svatyuk N., Parlag O., Shpenik O., Sukharev S. Radionuclide monitoringin Transcarpathian region: the role natural and antropogenic factors. Acta facultatis studiorum humanitatis et naturae universitatis presoviensis. Natural sciences. Biology-ecology. Preshov, Slovac republic. 2016. 43, № 6. P. 112-120.

Надійшло до редакції 13.09.2021

\section{REFERENCES}

1. Chau, N. D., Lucyna, R., Nowak J., \& Jodłowski P. (2012). Radium isotopes in the Polish Outer Carpathian mineral waters of various chemical composition. Journal of Environmental Radioactivity, 112, pp. 38-44.

2. Badawy, W. M., Duliu, O. G.,. Frontasyeva, M. V., El Samman, H. \& Faanhof, A. (2018). Environmental radioactivity of soils and sediments: Egyptian sector of the Nile valley, Isotopes in Environmental and Health Studies, 54, Iss. 5, 535-547. https://doi.org/10.1080/10256016.2018.1482292

3. Okhrana pryrodu. Hydrosfera. Obshchye trebovanyia k otboru prob donnukh otlozhenyi vodnukh obъektov dlia analyza na zahriaznennost: HOST 17.1.5.01-80 [Vved. 01.01.81]. Moscow: Hoskomytet SSSR po standartam, 1981. 6 s. (in Russian).

4. Orhanyzatsyia y provedenye nabliudenyi za soderzhanyem zahriazniaiushchykh veshchestv v donnukh otlozhenyiakh vodnukh obyektov: RD 52.24.609-2013. [Vved. 02.09.2013]. Rostov-na-Donu: Roshydromet, 2013. 43 s. (in Russian).

5. Dikiy, N. P., Lyashko, Yu. V, Medvedeva, E. P., Medvedev, D. V, Parhomenko, Yu. G. \& Fedorets, I. D. (2017). The content of natural radioactive isotopes in soil of Kharkov region. Problems of atomic science and technology. Series: Nuclear Physics Investigations, 3 (109), pp. 55-59.

6. Maslyuk, V., Svatyuk, N., Stets, M., Frontasyeva, M. \& Parlag, O. (2013). Statistical regularities in the distribution of radionuclides in sediments of Transcarpathia mountain rivers. Journal of Environmental Radioactivity, 117. P. 9-12. https://doi.org/10.1016/j.jenvrad.2012.04.016

7. Svatiuk, N. I. \& Symochko, D. M. (2010). Radioecology of Transcarpathian mountain Rivers: Time and Spatial Correlations. Nuclear Physics and Accelerators in Biology and Medicine. Fifth International Summer School edited by A.Dubnichkova, S. Dubnichka, C. Granja, C. Leroy, I. Stekl. AIP Conference Proceedings; 1/5/2010, 1204. Iss. 1, pp. 263-264.

8. Symkanich, O., Maslyuk, V., Svatyuk, N., Parlag, O., Shpenik, O. \& Sukharev, S. (2016). Radionuclide monitoringin Transcarpathian region: the role natural and antropogenic factors. Acta facultatis studiorum humanitatis et naturae universitatis presoviensis. Natural sciences. Biology-ecology. Preshov, Slovac republic, 43, 6, pp. 11-120.

Received 13.09.2021 
N.I. Svatiuk1, https://orcid.org/0000-0001-9022-9252

V.I. Roman ${ }^{1}$, https://orcid.org/0000-0003-2499-8357

O.M. Pop ${ }^{1}$, https://orcid.org/0000-0002-5690-1030

O.I. Simkanich ${ }^{2}$, https://orcid.org/0000-0002-9948-1742

I.V. Pylypchynets ${ }^{1}$, https://orcid.org/0000-0002-0120-7703

${ }^{1}$ Institute of Electron Physic of the NAS of Ukraine, Uzhhorod

${ }^{2}$ Uzhhorod National University

E-mail: natashasim777@gmail.com, viktoriyaroman11@gmail.com

\section{RADIOISOTOPE STUDIES OF THE TISZA RIVER BASIN, UZHANSKY MASSIF}

The results of applying nuclear-physical research methods of determination of the radioisotope composition of bottom sediments and soils of the Tisza river basin, on the example of the Uzh river on the Transcarpathian territory are presented. The database of contents for natural and man-made gamma-active nuclides is obtained using the low-background gamma spectrometry method. The results obtained are essential for setting the standards for their content and for the study of mountain areas. The possibility to establish $\mathrm{U} / \mathrm{Th} / \mathrm{K}$ chemical components in the bottom sediments of the Uzh river is shown. The results of radioisotope research allow modeling the processes of migration pf gamma-active nuclides from reservoirs into the soil horizons of the studied areas. These data are important for predicting the transboundary migration of gamma-active nuclides.

Keywords: composition of radioisotopes, man-made and natural nuclides, specific content, accumulationdistribution, U/Th abundances. 